\title{
O autismo visto como complexa e heterogênea condição
}

SILBERMAN, Steve.

Neurotribes: The legacy of autism and the future of neurodiversity.

New York: Penguim Random House, 2015, 534p.

| ${ }^{1}$ Pedro Henrique Corrêa |

${ }^{1}$ Mestrando, Programa de Saúde Coletiva, Instituto de Medicina Social, Universidade do Estado do Rio de Janeiro. Rio de Janeiro-RJ, Brasil (pedrocorreapsi@gmail.com).

The legacy of autism and the future of neurodiversity, lançado em 2015, ganhou diversos prêmios nos Estados Unidos e foi traduzido para mais de 13 línguas, apesar de infelizmente ainda não ter sido publicado em português. Esta resenha visa apresentar a obra ao público brasileiro em primeira mão através da Revista Physis, tentando despertar o interesse para a leitura por todos aqueles que pesquisam ou buscam conhecer essa condição tão complexa e heterogênea, como definiu Silberman, que é o autismo. Além disso, quem sabe a resenha possa despertar o interesse para uma merecida tradução.

Steve Silberman escreveu, além de Neurotribes, diversos artigos que apareceram em publicaçōes midiáticas e científicas de renome em todo o mundo. Sua profissão é de escritor, mas tem formação acadêmica em Psicologia e Literatura. Certamente o hábito jornalístico de dar voz às pessoas foi crucial na atitude investigativa de Silberman. Mas o que afinal o autor investigou e no que constitui sua descoberta fundamental para que sua pesquisa tenha se tornado tão célebre em diversos espaços?

O livro já começa interessante com o prefácio escrito por Oliver Sacks para os que não o conhecem, Sacks faleceu em 2015 e foi renomado professor, neurologista e autor de diversas obras que também se tornaram best-sellers nos Estados Unidos -, que classifica a obra como uma história completa e penetrante 
quanto ao que pretende investigar. Segundo ele, Silberman foi a única pessoa que conheceu disposta a investir a maior parte do seu tempo para simplesmente escutar e tentar entender o que seria o autismo, em uma atitude ao mesmo tempo científica e militante.

O fruto da leitura desse livro por todo o mundo teve um impacto tão grande no modo como se pensava o autismo, que é esperado que dentro dos próximos anos ele se torne leitura obrigatória em cursos sobre o tema e uma das citaçôes favoritas nas publicações científicas.

A obra está dividida em 12 capítulos, sendo que a divisão está longe de ser arbitrária. Através dela, Silberman fará uma contextualização sobre o autismo que passa desde histórias particulares, até movimentos organizados por autistas e familiares, fincando pilares na exploração da origem médica da "patologia" (conceito criticado pelo movimento da neurodiversidade), origem esta que ainda carrega muitos mistérios, sobretudo por trás dos renomados cientistas envolvidos na pesquisa, que devem ser desvendados historicamente. As histórias ao longo da obra são contadas em linguagem leve, jornalística, que retrata o dia a dia de diversas pessoas atravessadas por uma série de questóes que as destacavam da maioria. As questões, se não levaram essas pessoas a serem classificadas como autistas por viverem em uma época anterior ao diagnóstico, no mínimo contribuíram para serem taxadas de excêntricas, bizarras. Junto às histórias, Silberman não deixou de fazer comentários baseados em sua experiência, muitos carregados de críticas, algumas sutis e outras explícitas, à maneira que vemos a condição autista hoje, como predominantemente uma "deficiência". É esse mito que as histórias de pessoas espetaculares vão quebrando ao longo das mais de 500 páginas, apesar de não ser demorado o processo no qual o leitor percebe um teor de contestação na obra.

No primeiro capítulo, por exemplo, após contar a história de vida de dois cientistas com hábitos bem estranhos, mas com contribuições imensas para a humanidade, comentou que "é difícil imaginar o estado do mundo moderno se esses dois renomados cientistas não tivessem nascido". ${ }^{1}$ Henry Cavendish, nascido no século XVIII, poderia facilmente ser encaixado em um tipo de autismo segundo o DSM se avaliado por um psiquiatra do século XXI. Ao contrário do que se poderia esperar na contemporaneidade, os hábitos excêntricos tanto de Henry quanto de Paul Dirack, o segundo cientista exposto, foram incentivados 
por suas famílias e amigos. Além disso, suas excentricidades eram tratadas com um ar de diferença mais do que como malefícios à pessoa. Como resultado desse outro contexto histórico, independentemente das atitudes antissociais ou da rotina inflexível das duas figuras, os dois jovens puderam realizar descobertas que impactaram e garantiram novos rumos para a ciência.

No segundo e no terceiro capítulo, outros personagens e suas peculiaridades participam dessa obra, sempre de maneira ilustrativa quanto à potencialidade vinda da diferença. No terceiro capítulo, em especial, entrará a figura de Hans Asperger, pesquisador austríaco que ao longo de uma década examinou mais de duas centenas de crianças com "estranhezas", além de adultos com os mesmos perfis. Para o autor, quem foi acolhido e tratado pelo psiquiatra Hans Aspeger estava "no lugar certo", na única clínica do mundo que poderia dar a atenção e o cuidado necessário às crianças trazidas pelos familiares.

A partir do quarto capítulo, entra a figura do do psiquiatra austríaco Leo Kanner, que afirmou que havia "descoberto" uma nova patologia - e o emprego das aspas ficará claro no parágrafo seguinte. Kanner, em seu famoso trabalho divulgado em 1943, intitulado "Autistic disturbances of affective contact", mostrou os resultados de uma pesquisa realizada com 11 crianças que tinham em comum, segundo ele, isolamento extremo e desejo de preservação do mesmo. A origem dessa condição seria o resultado de uma relação fria entre o bebê e seus cuidadores, propiciada sobretudo pela frieza e distância da mãe para com seu filho. Frequentemente, o termo "mãe-geladeira" é atribuído ao psicanalista Bruno Bettelheim, mas sem dúvida foi Kanner que inaugurou a frieza da mãe como hipótese da causa do autismo, concepção que posteriormente foi apropriada por diversos médicos, psicólogos e psicanalistas. Para proteger-se de críticas, Leo Kanner classificou o autismo como inato, formulação não incorporada na teoria de Bruno Bettelheim.

Silberman descobriu, porém, a partir de trabalhos da psicóloga cognitiva inglesa Lorna Wing, que a história sobre a pesquisa do autismo poderia estar sendo profundamente distorcida, ocultando uma verdade chocante que se pode mudar toda a forma como vemos a origem das investigaçóes sobre essa condição, e até mesmo a própria condição. $\mathrm{O}$ choque com o diagnóstico de autismo formulado por Kanner começou quando a psicóloga realizou, na década de setenta, uma pesquisa com crianças autistas em um subúrbio de Londres. Lá 
Lorna encontrou muito mais pessoas próximas ao diagnóstico de autismo do que Kanner havia previsto em sua pesquisa.

Para buscar a explicação dessa extrapolação nos números firmados por Kanner sobre a abrangência do autismo, Lorna buscou novas referências, o que a fez encontrar escritos em alemão de Hans Asperger. Este, diferentemente de Kanner, até então não tinha tido seus escritos traduzidos para inglês. O choque de Lorna foi constatar que o que ela estava vendo acontecer em Londres estava muito mais próximo ao que Asperger descrevia em suas pesquisas, realizadas em Viena, do que ao que Kanner explicava em seus trabalhos nos Estados Unidos. Além disso, Kanner nunca mencionou as pesquisas de Asperger em seus textos, apesar de terem sido realizadas antes.

Ou seja, Lorna descobriu que Asperger estava pesquisando sobre crianças com sintomatologia muito próxima às de Kanner, cinco anos antes deste anunciar ter "descoberto o autismo". E aí está a explicação do uso das aspas no início do texto para se referir à "descoberta" de Kanner. Sem dúvida, a história e o percurso da descoberta até a primeira classificação de qualquer sintoma na forma de diagnóstico psiquiátrico influenciam a percepção de todos sobre o sujeito diagnosticado. E o que o autor do livro nos mostra é a documentada história da descoberta do autismo que não teve origem em Kanner, mas em Asperger na década de 1930.

Ao contrário do que muitos pensam, Asperger não descobriu apenas a condiçãao conhecida como síndrome de Asperger. O que ele descobriu junto a seus colegas na Universidade de Viena foi o que nós hoje chamamos frequentemente de espectro do autismo, ou em inglês, autistic continuum ou autistic espectrum. $\mathrm{O}$ grupo de pacientes pesquisados por Asperger foi diverso, incluindo uma criança muda, outra que balançava suas mãos constantemente, e outra que coletava dados minuciosos sobre astronomia. O nome diagnóstico proposto por Asperger para esses casos foi "psicopatia autística". Em suma, Kanner formulou o autismo como uma condição muito mais estrita e bem delineada, relacionando-a com a psicose infantil e definindo sua prevalência como quatro em cada dez mil pessoas. Já Aspeger relacionou tanto aspectos clínicos quanto pedagógicos em suas investigaçôes, o que constrói um quadro clínico bem mais amplo do que aquele definido posteriormente por Kanner.

Após a invasão nazista, Asperger foi forçado a encerrar suas pesquisas, que iam contra o programa nazista de purificação da raça humana, a eugenia. Muitos dos 
pesquisados tiveram que fugir ou cometeram suicídio. Até mesmo um colega de Asperger tornou-se um dos líderes do extermínio secreto de crianças deficientes. A divisão diagnóstica proposta por Asperger entre autistas de alto e de baixo funcionamento surgiu nesse contexto e foi uma das maneiras de proteger a vida das crianças em sua clínica.

Além da descoberta sobre o pioneirismo de Asperger na pesquisa sobre o autismo, Silberman afirma ter reunido evidências de um fato ainda mais perturbador: Kanner foi um homem sedento por escrever seu nome na história da medicina e estava disposto a realizar atos eticamente condenáveis para atingir seus objetivos. A consequência do quadro diagnóstico estreito de Kanner, resultado de uma opção por esconder pesquisas anteriores, foi que muitos autistas e familiares foram negligenciados e não noticiados, resultando em falta de assistência social. A própria não tradução do trabalho anterior realizado por Aspeger pode ser atribuída à omissão consciente de Kanner. Silberman, portanto, classifica o pai fundador da psiquiatria infantil como culpado pelo sofrimento de muitas famílias. A psicóloga Lorna Wing tinha um filho autista e estava consciente dos desafios que os familiares de crianças autistas, principalmente do subúrbio de Londres no qual realizou sua pesquisa, tinham para acessarem serviços sociais de apoio.

Fala-se muito sobre o aumento do número de crianças diagnosticadas como autistas nas últimas décadas. Esse aumento está sem dúvida alguma relacionado à ampliação gradual nos critérios diagnósticos. No DSM-5, por exemplo, foi extinta a divisão entre síndrome de Asperger e autismo. Lorna, antes mesmo dessa mudança, silenciosamente trocou o critério diagnóstico de autismo de Kanner pelo de Asperger em seus trabalhos - tudo isso em uma época em que o autismo era considerado muito raro. E fez isso imbuída do desejo de que mais famílias tivessem acesso a serviços de saúde, os quais apenas o diagnóstico de autismo poderia fornecer.

Nos últimos três capítulos, Silberman defende que a noção de que a cura para os mais incapacitantes aspectos do autismo será encontrada em uma pílula é falsa. Para ele, as comunidades solidárias (supportive communities), que são locais onde os autistas se autogestionam de acordo com suas próprias necessidades, são a opção mais adequada de tratamento, neles sendo fornecidas condições adequadas para que os autistas possam experimentar sua forma de estar no mundo de maneira plena. 
De modo geral, Silberman, em seu livro, representa demandas de pessoas que precisavam de diagnóstico e que foram esquecidas e excluídas pela psiquiatria e pelo DSM por muito tempo, o que resultou em sofrimento desnecessário. Hoje, apesar dos avanços, principalmente no reconhecimento jurídico, o cenário não é animador. Milhôes de dólares estão sendo investidos em pesquisas que buscam a causas do autismo na genética e em agentes microscópicos ambientais; até mesmo antidepressivos na água e poluição do ar estão sendo relacionados a essa condição. Enquanto isso, pouco dinheiro está sendo direcionado para ajudar crianças e adultos autistas e seus familiares a terem melhores condições de vida. $\mathrm{O}$ que o autor do livro nos chama à atenção todo momento é que nossa sociedade precisa repensar a maneira pela qual está lidando com o autismo.

Ao final do livro, Silberman faz sua avaliação: é preciso superar a obsessão pelo encontro das causas dessa condição, assim como hoje se problematiza a necessidade do encontro das causas da esquizofrenia. Não sabemos as causas exatas da esquizofrenia e isso não quer dizer que devemos deixar de dar assistência às pessoas envolvidas. Partes dos recursos que estão sendo aplicados hoje em pesquisas genéticas e ambientais seriam muito mais úteis se ajudassem diretamente os que sofrem. É aí que está um dos principais fatores que destacam a importância da obra de Silberman na contemporaneidade: seu caráter militante e sua crítica científica sobre como vemos e tratamos uma condição complexa e heterogênea como o autismo.

\section{Nota}

${ }^{1}$ Tradução livre do autor. 